\title{
A comunicação, entre o dogma e a conversão: o especificamente comunicacional na religiosidade contemporânea*
}

\author{
Luiz Signates $^{* *}$
}

\section{Resumo}

Este texto questiona a religião como espaço típico dos estudos de comunicação voltados para o estudo da centralidade da comunicação na compreensão dos processos sociais. Pressupõe-se que o mundo religioso bordeja os limites da comunicabilidade, tanto quanto da incomunicabilidade. $\mathrm{Na}$ tensão entre a conversão e o dogma, se distinguem as relações religiosas pela dependência de processos comunicacionais, ao mesmo tempo em que carecem fortemente do silenciamento no âmbito do dogma, para a manutenção das identidades e instituições. Por ser lugar da realização e da manutenção de limites comunicacionais, é o mundo religioso, hipoteticamente - melhor até do que as mídias -, o lugar por excelência da investigação pelo especificamente comunicacional na sociabilidade contemporânea. Assim, as possibilidades e os limites da dialogicidade humana podem, por isso, ser tensionados com grande visibilidade metodológica no campo religioso, especialmente no contexto de pluralidade e diversidade religiosa das sociedades contemporâneas.

Palavras-chaves: Comunicação e religiosidade. Religião e comunicabilidade. Comunicação e dialogicidade.

\section{Communication, between dogma and conversion: the specific communication conception in contemporary religiousness}

\footnotetext{
Abstract

This text questions religion as the typical space of communication studies, in the study of the centrality of communication. It is assumed that the religious world borders on

* Uma versão prévia deste trabalho foi aprovada para apresentação no Simpósio Temático "Espiritualidades contemporâneas, pluralidade religiosa e diálogo", do Congresso Lusófono de Ciência das Religiões, ocorrido em Lisboa, Portugal, em 2015.

** É docente efetivo dos PPGs Ciências da Religião (PUC-Goiás) e Comunicação (UFG). Doutor em Ciências da Comunicação (USP).
} 
the limits of communicability, as well, as incommunicability. In the tension between conversion and dogma, religious relations are distinguished by the dependence of communicational processes as they lack the silencing in the scope of the dogma, in the maintenance of the identities and institutions. Because it is a place for the realization and maintenance of communication boundaries, it is the religious world - even better than the media - the privileged place for research, taking into account the specifically communicational issue in contemporary sociability. Thus, the possibilities and limits of human dialogicity can be tensioned with great methodological visibility in the religious field, especially in the context of plurality and religious diversity.

Keywords: Communications and religiosity. Religion and communicability. Communication and dialogicity.

\section{La comunicación, entre el dogma y la conversión: el especificamente comunicacional en la religiosidad contemporánea}

\section{Resumen}

Este texto cuestiona la religión como espacio típico de los estudios de comunicación dirigidos al estudio de la centralidad de la comunicación en la comprensión de los procesos sociales. Se supone que el mundo religioso bordea los límites de la comunicabilidad, tanto de la incomunicabilidad. En la tensión entre la conversión y el dogma, se distinguen las relaciones religiosas por la dependencia de procesos comunicacionales, al mismo tiempo que carecen fuertemente del silenciamiento en el ámbito del dogma, para el mantenimiento de las identidades e instituciones. Por ser lugar de la realización y del mantenimiento de límites comunicacionales, es el mundo religioso, hipotéticamente - hasta mejor que los medios -, el lugar por excelencia de la investigación por lo específicamente comunicacional en la sociabilidad contemporánea. Así, las posibilidades y límites de la dialogicidad humana pueden, por tanto, ser tensadas con gran visibilidad metodológica en el campo religioso, especialmente en el contexto de pluralidad y diversidad religiosa de las sociedades contemporáneas.

Palabras clave: Comunicación y religiosidad. Religión y comunicabilidad. Comunicación y diálogo.

\section{Introdução}

As ciências da comunicação, em seus estudos, em todo o mundo, têm registrado alguns processos e instituições como específicos e tradicionais, para a constituição de seu corpus de pesquisa. Em geral, um desses lugares sempre foi percebido como óbvio: a mídia. E isso tanto pela atratividade das novas tecnologias de comunicação, que revolucionaram os suportes simbólicos de transmissão de ideias na História, quanto pela transformação que operou nos modos de relacionamento das sociedades, das formações culturais e tradições.

A mídia foi a instituição que, de fato, tornou concreta, pela primeira vez na história humana, um sentido sistêmico, no sentido habermasiano, da 
comunicação, isto é, como instituição específica, dotada de interesses, linguagens e ritual produtivo próprio. $\mathrm{O}$ que era uma habilidade especificamente humana, a de se relacionar pela linguagem com o mundo e os outros, tornou-se um saber técnico cioso de sua legitimidade e de sua exclusividade.

Essa peculiaridade institucional das mídias, contudo, terminou por restringir a noção de comunicação a condições institucionais que dificultam a emergência de um conceito suficientemente forte, como o que se busca, quando se pergunta, como na sequência de trabalhos que temos desenvolvido, pelo especificamente comunicacional. ${ }^{1}$ Em termos epistêmicos, a tese é de que a simples admissão de que as mídias são o lugar da comunicação pode obscurecer a delimitação do objeto de pesquisa, já que muitos são os objetos e disciplinas científicas pelos quais se pode estudar as instituições midiáticas. Mídias são empresas, logo são objeto válido de estudos que perpassam desde a ciência da administração e a economia até a sociologia do trabalho; mídias são operadores tecnológicos, podendo, como tais, serem estudadas pela perspectiva da engenharia e da informática; mídias são formadoras de esferas públicas em todos os âmbitos sociais, constituindo, portanto, objetos interessantes para perspectivas sociológicas e antropológicas diversas... E assim por diante.

Nesses termos, faz sentido estabelecer a pergunta problema: afinal, o que é o especificamente comunicacional nas mídias? Até que ponto o sistema midiático é expressão de uma noção de comunicação que pode ser universalizada a ponto de dar conta da dimensão de objeto de pesquisa específico e distinto dos estudos comunicacionais?

Este trabalho efetuará um questionamento nesse sentido, a fim de empreender o estudo da religião como lugar privilegiado para estudos da comunicação e, dessa operação, se procurará estabelecer algumas condições epistemológicas, epistêmicas e metodológicas que possam contribuir não apenas para delimitar o objeto comunicacional, como para evidenciar, em suas possibilidades e limites, a propositura hipotética de que a religião ou a

\footnotetext{
Este texto se inscreve nos estudos epistemológicos da comunicação que tem feito o autor há vários anos, como empreendimento pela caracterização do objeto das ciências da comunicação, em uma perspectiva que admite a primazia dos estudos de religião e, nesse sentido, efetua a busca pelo que é especificamente comunicacional nas práticas religiosas. Uma das questões fundamentais para que se dê sequência consistente ao estudo do especificamente comunicacional - e por conseguinte, se busque estabelecer as condições para a delimitação do objeto da comunicação - tem sido a escolha de um "lugar" social ou humano onde esse objeto melhor se mostre, em que sua visualização permita com mais nitidez o desentranhamento do objeto, em suas peculiaridades e características.
} 
religiosidade constitui lócus privilegiado para os estudos comunicacionais e, mais ainda, que seu estudo pode oferecer significativa contribuição para a compreensão do religioso enquanto tal.

\section{As instituições de poder simbólico como lugares da comunicação}

Segundo Bourdieu, o poder simbólico é aquele exercido pelo processo de circulação da linguagem no meio social: "o poder simbólico como poder de constituir o dado pela enunciação, de fazer ver e fazer crer (...) ...só se exerce se for reconhecido" (BOURDIEU, 1989, p. 14). Ao estabelecer a noção de poder simbólico, Pierre Bourdieu desde o princípio vinculou o conceito aos sentidos da comunicação. Para ele, "as relações de comunicação são, de modo inseparável, sempre, relações de poder que dependem, na forma e no conteúdo, do poder material e simbólico acumulados pelos agentes" (BOURDIEU, 1989, p. 11).

Bourdieu, contra o estruturalismo, não teoriza a perspectiva institucional. Seu estudo abrange os campos sociais, o que inscreve sua sociologia no âmbito das sociologias da ação social, ou no que ele mesmo denominou como sendo uma sociologia reflexiva.

A dicotomia entre teorias da ação e teorias sistêmicas se manteve até Habermas (2012). Na Teoria da Ação Comunicativa, esse autor efetua a combinação entre sistema e mundo da vida, como âmbitos normativos da disjunção entre poder e sociedade, configurando dois mundos diferentes, em conflito entre colonização e resistência - ou, no sentido de Boaventura Santos (1997), entre regulação e emancipação.

Em nosso trabalho (SIGNATES, 2009), efetuamos uma reinterpretação do processo colonizador em Habermas, a partir do conceito de "institucionalização sistêmica", e o aplicamos ao desenvolvimento da comunicação na modernidade (quando uma habilidade especificamente humana se converte em um sistema institucionalizado, desengastando a condição pública da comunicação do âmbito do mundo da vida).

Hipoteticamente, uma das principais dificuldades de compor o especificamente comunicacional a partir dos estudos de mídia é essa natureza contraditória da comunicação midiática. O desentranhamento da comunicação dos processos comunicativos interpessoais e a sua consequente institucionalização sistêmica redimensionaram os sentidos da comunicação, lançando-a, de uma vez por todas, no âmbito das ações estratégicas e 
instrumentais. A comunicação assim colonizada perde seus sentidos especificamente comunicacionais, embora, como todo sistema, conforme Habermas, não tenha podido desenraizar-se completamente do mundo da vida, na medida em que tais instituições, mesmo estruturadas por ações performáticas, não deixa de depender da linguagem.

O processo de institucionalização sistêmica é correspondente ao que Habermas denomina "colonização" do mundo da vida. Entretanto, o autor alemão não enxerga esse processo ocorrendo com a própria comunicação, originando-se uma dupla e dúbia natureza, a comunicativa e a estratégicoinstrumental, a vivida e a institucionalizada.

Isso porque, para Habermas, a relação de linguagem não se configura em poder, na medida em que os interlocutores podem, pragmaticamente, dizerem "não" (HABERMAS, 2012). Com isso, Habermas se afasta de abordagens tais como a de Foulcault e de Bourdieu.

Em trabalho anterior (SIGNATES, 2009), estabelecemos a crítica a Habermas, a partir do reconhecimento, nos termos da teoria da ação comunicativa, de que a comunicação igualmente sofreu um processo de colonização do mundo da vida, no desenvolvimento das organizações de mídia, e, com isso, tornou-se condição derivada à conclusão de que, ao contrário do que formulou o autor alemão, a linguagem se tornou vítima dessa colonização, transformando-se, na manipulação da simbólica pública, em meio de exercício de poder.

Com isso, a indagação é: que tipo de poder exerce a linguagem, colonizada sistemicamente? Será primeiro Foucault, depois Bourdieu, os que melhor responderam a essa pergunta. Bourdieu identifica em sua sociologia da ação a formação de campos simbólicos, nos quais se realiza a disputa pelas regras da produção do sentido e, por conseguinte, dos processos de legitimação que participam das formações identitárias dos próprios campos simbólicos, em sua busca por autonomia, em relação aos demais campos e à própria sociedade. Trata-se do poder simbólico, aquele movimentado pelos campos sociais, dentro dos conflitos por legitimação. Bourdieu, contudo, não insere a perspectiva das instituições em sua teorização.

Em Foucault (1997), identifica-se uma microfísica do poder, como modo de produção e de reprodução do poder, nas próprias marcas da linguagem em circulação na sociedade. Poder diluído socialmente, que não estaria, como classicamente se pensa, localizado aqui ou ali, mas que funciona em rede. É o discurso, a marca identitária da linguagem, nesse sentido. E 
tais discursos tomam a forma de institucionalidades, que demarcam, mas atravessam os campos sociais como tais.

A partir da discussão crítica de Foucault, Bourdieu e Habermas, tornase possível o reconhecimento das instituições de poder simbólico, assumidas como tais por Thompson (2009), numa perspectiva muito parecida com a ideia de discurso de Foucault, porém dentro de uma sociologia específica, o que o aproxima de Bourdieu e Habermas.

Em nosso trabalho, destacamos as simbólicas próprias de todo e qualquer campo social daquelas em que as próprias institucionalidades se revertem do caráter simbólico do poder, como movimentações fundadoras de sua própria razão de ser. Assim, as instituições de poder simbólicos são aquelas formadas dentro de quatro campos específicos: o midiático, o escolar, o religioso e os movimentos sociais. Cada campo possui suas peculiaridades específicas e, dessa forma, se institucionaliza sistemicamente.

Neste trabalho, avaliaremos aquele que tem sido considerado "natural" dos estudos de comunicação: o campo midiático, e, a partir dessa breve análise, considerar as vantagens para os estudos da comunicação da eleição do campo religioso como lugar dos estudos de comunicação.

\section{O estudo do especificamente comunicacional na mídia e seus limites}

Não há que se negar que a mídia constitui uma instituição de natureza comunicacional. Seu caráter de mediação entre os campos construtores da legitimidade nas sociedades contemporâneas lhe dá esse caráter, que Adriano Rodrigues denomina caráter "vicário" ou "delegado", pelo qual o campo das mídias se expressa por delegação dos outros campos sociais produtores de sentido (RODRIGUES, 2001).

Entretanto, nem toda a atuação da mídia se reveste desse caráter específico. Com o aprofundamento e a consolidação de seu processo de institucionalização sistêmica (SIGNATES, 2009), cada vez mais as instituições midiáticas se tornaram sujeitos de seus próprios discursos, orientados por interesses que lhes são específicos, e não apenas mediadores entre campos sociais dotados de legitimidade. Ao contrário, os demais campos sociais é que tiveram que se adequar às linguagens e ritualidades das diferentes formas midiáticas de comunicação, para conseguirem acesso e visibilidade em seu interior, ganhando condições, assim, de se expressar publicamente.

Esse caráter sistêmico das instituições midiáticas torna pertinente a questão sobre o que há de especificamente comunicacional nessas 
organizações. Este trabalho parte do princípio de que nem sempre as mídias são meios de comunicação ou funcionam como tal (SIGNATES, 2009; GOMES, 2004). Entretanto, o aspecto comunicacional delas exsurge exatamente quando assim funcionam. É o silenciamento midiático do que lhe é próprio, para dar lugar à expressão do outro social, quem quer que ele seja, o que constitui o especificamente comunicacional na mídia.

Essa posição talvez expresse um axioma: para que a mídia se comunique, é preciso falar em silêncio. Esse paradoxo é apenas aparente. Por silenciamento não se quer dizer fazer silêncio num sentido literal e sim silenciar-se para conceder a atuação própria simplesmente como "médium". O ato de "dar lugar" ou "deixar falar o outro" é uma condição especificamente comunicacional, nesse sentido. Em outros termos, trata-se de algo próximo ao silenciamento da escuta psicanalítica, que sempre deve vir seguido da fala do analista, que não é dele - ao menos não apenas ou principalmente - e sim do analisando, que se escuta na fala do analista. Eis o especificamente comunicacional.

Ao operar ou concentrar sua fala em seus próprios interesses, as instituições de mídia tornam-se surdas e, assim, incomunicativas. Evidentemente, não deixam de ser mídias ou midiáticas, por se distanciarem ou até perderem o caráter especificamente comunicacional. Em outras palavras, a mídia fala, mesmo quando não se comunica especificamente. É razoável admitir que tais estados não existem puros em momento algum, e sim constituem, na análise aqui empreendida, parâmetros, categoriais ou normativos do reconhecimento conceitual da comunicação. Na maioria das vezes, o comunicacional e o não comunicacional se enovelam de modo complexo, nas situações reais. É, contudo, teoricamente proveitoso estabelecer tais disjunções conceituais, a fim de empreender a análise das condições teóricas e metodológicas de se situar a mídia como objeto primaz dos estudos de comunicação.

Percebe-se, pois, que a alteridade é constitutiva da especificidade da comunicação, embora não necessariamente o seja da comunicação em si. Em outros termos, o vínculo comunicacional pode se dar sem alteridade, isto é, de forma "surda", contudo, nesses casos os espaços simbólicos decorrem invadidos por interesses e resultantes não comunicacionais, o que lhes retira a especificidade.

O exemplo das mídias parece típico dessa disjunção entre o vínculo comunicacional e o que lhe é específico. Ao operar a partir de seu caráter institucional e sistêmico, as organizações de mídia atuam orientadas não 
obrigatória ou principalmente para suas audiências, e sim para agentes que agem indiretamente sobre os sistemas institucionais, como os anunciantes e, não raro, as instituições de poder, sobretudo o Estado. Esse estar a serviço de outro que não o interlocutor, moldando a interlocução e a falseando, contribui para relativizar o caráter especificamente comunicacional das operações simbólicas movimentadas pelas mídias, em suas linhas editoriais e programações de conteúdo.

A atuação das mídias é, pois, especificamente comunicacional se e quando opera de forma aberta ou como meio de comunicação. Em outras palavras, quando dá ao outro a condição de fala, isentando-se do processo.

Outra condição que pode ser julgada como especificamente comunicacional seria a interlocução, o diálogo, desde que igualmente em condições de alteridade. As mídias de massa, contudo, não são prioritariamente interativas e, quando o são, usualmente mantêm entrevistados e participantes em condições de estrito controle de fala e tempo, reduzindolhes a possibilidade de igualdade comunicativa. A desigualdade na situação de interlocução, especialmente quando se ajusta a controles técnicos sobre os quais apenas um dos falantes possui poder, por constituir um anulador pragmático da situação alteritária, reduz também a especificidade comunicacional dos processos midiáticos.

Tais restrições, contudo, são dificilmente operacionalizáveis em pesquisa, uma vez que os sistemas circunstritores são usualmente maquiados. As mídias ocultam sempre seus interesses estratégicos, a fim de se fazerem parecer comunicacionais. A conhecida confusão entre liberdade de expressão, liberdade de imprensa e liberdade de empresa parece um caso típico desse ocultamento, que torna particularmente difícil o mapeamento do especificamente comunicacional nos estudos sobre os sistemas de mídia.

Assim, nem tudo nas mídias é comunicação e o que se pode denominar comunicação ultrapassa o mero funcionamento das mídias. Por isso, a ideia de que os estudos de mídia são necessariamente estudos de comunicação tornase um fator de obscurecimento do objeto de uma ciência da comunicação, razão pela qual parece legítimo efetuar a busca por outro corpus de pesquisa, a fim de melhor mapear o especificamente comunicacional na comunicação.

\section{O religioso como lugar dos estudos de comunicação}

Os campos religioso e midiático são, ambos, fortemente vinculados e dependentes dos processos de produção, reprodução e circulação de 
bens simbólicos. Entretanto, a religião possui peculiaridades que a tornam específica para os estudos comunicacionais, que em geral se fazem ausentes ou no mínimo não fortemente presentes nos demais campos, inclusive no midiático. Perscrutemos rapidamente alguns (os limites deste trabalho não permitem o aprofundamento que seria necessário para dar conta dos desafios teóricos desta posição), que facultem traçar um caminho para discernir sobre o especificamente comunicacional na religião.

A ideia enunciada no item anterior, de estabelecer a comunicação a partir das condições de alteridade, e que encontra nas mídias a limitação complexa de seu processo de institucionalização sistêmica, aparece nos processos religiosos de forma muito mais nítida. Evidentemente, a religião também tem sua institucionalização sistêmica, na disjunção igreja/ experiência, que em geral se revela na conflitualidade sacerdote/profeta ou, em termos hermenêuticos, teologia/revelação ou mito/rito. Entretanto, não se trata, simplesmente, da dicotomia, já estabelecida pela antropologia e a filosofia da religião, entre sagrado e profano, pois as disjunções de natureza comunicacional ocupam todo o percurso da experiência religiosa.

Há, nesse sentido, um aspecto no qual o campo religioso se destaca, em termos comunicacionais, de todos os demais campos simbólicos: o seu forte caráter vinculativo. Em outras palavras, a religião é formadora e mantenedora de identidade cultural e, não raro, a ponto de absorver todo o pensamento e toda a prática da vida em seu interior. Nem os sistemas de mídia, nem a educação laicizada, nem mesmo os movimentos sociais - salvo os casos, muito comuns, de guardarem relações com sentidos religiosos - inserem-se no fenômeno em análise.

Esse vínculo identitário, por sua força pragmática, produz à pesquisa uma visibilidade extraordinária das tensões e conflitos comunicacionais, o que torna a religião um espaço onde as questões comunicacionais se tornam mais específicas e, por isso, avaliáveis. Observemos brevemente as marcas comunicacionais deixadas pela religião. Identificamos, nesse sentido, duas marcas fundamentais, que se tencionam mutuamente: o dogma e o vínculo. Tratemos rapidamente de cada um deles.

A primeira marca é o sentido comunicacional do dogma, definido aqui como sendo o lugar simbólico onde o valor da verdade religiosa alcança seu ápice. Não se define o dogma como "verdade absoluta", e sim como "verdade indiscutível". A diferença é de tipo comunicacional e bastante expressiva. Sem que haja a necessidade de ser imposto, isto é, estabelecido por um ato de 
violência simbólica, o dogma deve ser por definição admitido, numa relação em que a cognição o acessa não pela razão e sim num ato de fé. Como tal, o dogma não está disponível à interlocução, ao questionamento, à argumentação que não seja para reafirmá-lo.

$\mathrm{Na}$ busca pelo especificamente comunicacional, o dogma é o sinal exemplar da incomunicabilidade. E, nesse sentido, não aparece somente nos contextos religiosos, mas também em várias situações laicas, especialmente naquelas onde a ideia de verdade adquire importância definidora, como as ideologias em certos partidos e movimentos sociais, as verdades estabelecidas - ainda que relativamente - no debate científico (será Thomas Kuhn quem melhor descreveu o caráter dogmático que a ciência adquire, na processualidade social e histórica dos paradigmas) e, com mais inflexão, dentro das escolas, nas quais a verdade estabelecida pelo conhecimento ganha uma dimensão de "ordem" para que se considere "saber" certas proposições e não outras (FOULCAULT, 1997).

Enfim, não há dogmas somente nas religiões, mas é forçoso admitir que nessas o dogma adquire o seu caráter fundamental, como conhecimento específico do sagrado e, por isso, não disponível à comunicabilidade ou à dialogicidade.

A indisponibilidade para a comunicação, por mais absoluta que pareça, jamais poderá ser totalizante, sob o risco do solipsismo religioso, isto é, a total incomunicação ou a recusa de toda e qualquer relação social, mesmo aquela demarcada pelo dogmatismo, o que seria destrutivo da natureza mesma da religião ou da religiosidade. Desde o sentido etimológico, a religião é, em uma de suas mais relevantes apropriações de sentido, "re-ligar" (AZEVEDO, 2010), o que significa que, ainda que aprisionada em suas próprias verdades, a religião é atividade social por essência.

A característica necessariamente social de todo e qualquer fazer ou crença de tipo religioso conduz a uma espécie de corolário, que funciona como um princípio básico do estudo comunicacional da religiosidade, qualquer que seja ela: toda religiosidade institui uma tensão entre o dogma (incomunicabilidade) e os vínculos sociais necessários para a sobrevivência do fazer religioso enquanto tal (comunicabilidade). De certa forma, essa tensão entre a incomunicabilidade do dogma e a comunicabilidade dos vínculos reproduz-se na tensão fundadora da essência de toda e qualquer fé: os polos sagrado e profano. O sagrado, definido como sendo aquilo que está separado do mundo, constitui o lugar do significado estabelecido, inamovível, o núcleo 
fundador do dogma, sendo por tal razão que, não raro, a noção de sagrado é coligada à do indizível, da experiência noumênica, que os místicos não relutam em garantir não ser traduzível em qualquer linguagem articulada. E o profano, por sua vez, especifica o âmbito do contexto social e histórico da atuação religiosa, razão pela qual é possível afirmar que toda a comunicabilidade possível de qualquer religião é estabelecida na conexão desse mundo com as simbólicas do sagrado. Em outras palavras, a dicotomia sagrado/profano se articula comunicacionalmente na dualidade dogma/vínculo, de forma tal que a simbólica sustentadora do religioso enquanto tal está na tensão entre incomunicabilidade/comunicabilidade, metodologicamente localizável em quaisquer níveis das situações religiosas concretas.

Do ponto de vista da construção de modelos teóricos capazes de estabelecer essa teorização e lhe dar consequência metodológica, temos resistido a uma visão sistêmica da realidade religiosa, na qual a instância dogmática, comunicacionalmente inacessível, fosse localizada no centro do sistema, e os vínculos determinantes do sistema religioso se articulassem a partir do "núcleo duro" em direção às circunstâncias (relativamente indeterminadas) do "entorno" sistêmico. Nossa recusa deve-se sobretudo pela índole estruturalista ou organicista que essa formulação teórica poderia fazer desembocar os procedimentos analíticos, fazendo-nos perder o caráter eminentemente dialético do dualismo dogma/vínculo. Trata-se, para os termos deste trabalho, de um tensionamento, isto é, entre comunicabilidade e incomunicabilidade haveria sempre um conflito, inicialmente simbólico, mas possivelmente sociológico ou político, que seria hipoteticamente o principal responsável pelas disputas de tipo teológico, ritualístico ou de poder nas instituições religiosas e a partir delas, que poderiam ou não resultar nos cismas e nas guerras religiosas. Evidentemente, essa racionalidade conceitual e sua consequência hipotética são aplicáveis em princípio apenas à economia simbólica interna das movimentações religiosas, isto é, o âmbito intrarreligioso, embora, como veremos adiante, possam eventualmente ser articuladas com as disputas inter-religiosas. Tais reverberações da aplicação teórica, contudo, somente podem ser determinadas empiricamente.

É possível, no entanto, avançar em alguns tipos estabelecidos, da articulação entre dogma e vínculo, ou seja, entre incomunicabilidade e comunicabilidade, a partir da observação das religiões tradicionais e de suas peculiaridades. O polo do dogma se articula dialeticamente nos processos de funcionamento das religiões, a fim de se manter e se reproduzir na 
socialização religiosa e na tradição que lhe garante a permanência. A dogmática, em síntese, tem o que podemos denominar "repercussões pragmáticas", isto é, modos específicos de vínculo social da simbólica estabelecida no dogma ou, no sentido comunicacional, dispositivos comunicacionais destinados a fazê-lo circular e se reproduzir.

Assim percebido, o dogma não é simplesmente o centro da identidade, com seu alto caráter vinculante e agregador, formador de denominações e agrupamentos, nos quais o indivíduo tende a desaparecer, entregue aos sentidos da comunidade. Efetuando a análise a partir do pensamento comunicacional, é possível verificar pelo menos quatro repercussões pragmáticas do dogma sobre a vida religiosa - e aí temos tomado como objeto a vertente cristã, em suas inumeráveis divisões -, que enumeramos como sendo: o catecismo, o divulgacionismo, o conversionismo e o dialogismo. Tratemos, ainda que brevemente, devido às dimensões deste artigo, de cada um deles.

\section{a) Catecismo}

O catecismo é o lugar da socialização do dogma. O aspecto pedagógico desse tipo de comunicação aproxima e identifica o religioso com o escolar, lhe conferindo, contudo, especificidade de tipo dogmático, na medida em que a escola laica assumiu os demais sentidos que não sejam típicos da religiosidade. Surgido no século XVI, como um dos produtos religiosos da impactante invenção da imprensa, na esteira do impulsionamento protestante da alfabetização das massas na Europa moderna, e dirigida sobretudo a grupos populares e às crianças, o catecismo foi inicialmente fundamental na formação do cidadão cristão moderno, mas sempre demarcado pela necessidade institucional do controle, isto é:

...os catecismos têm como mensagem social e política dominante o conceito de dever e como prática a obediência (...). Neste sentido, o ensino religioso pode ser encarado como um meio ao serviço do Estado para disciplinar, urbanizar e racionalizar a vida dos homens (VAZ, 1998, p. 22-23).

A percepção mais atualizada da igreja estabeleceu, contudo, certas negociações de sentido com o conhecimento moderno, devidamente laicizado, implicando uma filosofia da educação catequética que seja capaz de absorver explicações de caráter filosófico e/ou científico: 
... (desde que não contradigam sua doutrina): dogmas, só os há para verdades de fé e não para filosofias. No entanto, as verdades de fé não são teoremas abstratos e desencarnados, harmonizam-se com as verdades naturais - quer provenham do conhecimento comum, da ciência ou da filosofia... - e, em certo sentido, delas dependem (LAUAND, 2000, s/p).

Observa-se que se fazem presentes as relações de tipo comunicacionais, especificadas na forma de negociações de sentido com os saberes hegemônicos ou social e historicamente legitimados, e, sempre, delimitadas pelas condições dogmáticas institucionalizadas, fora das quais passa a ocorrer o risco da fragmentação ou, no limite, da perda da identidade religiosa, pela diluição de seu núcleo estruturante. Tais negociações resultam nos textos e imagens catequéticas, que, uma vez estabelecidas, retornam à funcionalidade comunicacional de socialização original.

Nessa processualidade, que tipo de comunicabilidade se dá no ambiente catequético? Apenas aquela que objetiva resultar na formação do fiel ideal, daquele para quem o dogma é suficiente e bastante. A completude da crença é o critério de sucesso do esforço catequético, qualquer que seja a denominação ou vertente que a religião assuma. A comunicação possível, portanto, se dá num encaminhamento para o fechamento do discurso, no quadro da relatividade de sua condição social e histórica, e a partir do qual se estabelecem as possibilidades e limites da comunicação.

\section{b) Divulgacionismo}

A divulgação ou a propaganda religiosa é a condição de transcendência cognitiva do dogma. É a divulgação daquilo que proporciona, nas religiões cristãs, a condição simbólica de relacionamento com o mundo, que lhe é externo. Praticamente toda a vertente religiosa cristã estabelece divulgação de seus postulados, dentro de uma visão salvacionista e iluminista do processo comunicacional. Próximo do pedagógico, se diferencia deste pela sua peculiaridade argumentativa; enquanto no catecismo os sujeitos envolvidos já se predispuseram a admitir o dogma, sendo suficiente o seu ensino, na situação de divulgação os eventuais destinatários precisam ser primeiro convencidos da existência e das vantagens de adesão.

Mais do que do pedagógico, a divulgação se aproxima da institucionalidade midiática, em seu funcionamento, e, por essa razão, não raro a instituição religiosa trabalha por colonizar ou cooptar as mídias, 
apropriando-se de suas linguagens ou adquirindo fatias de programação. Nesse contexto, o sistema midiático ganha contornos efetivamente comunicacionais, mas a ação do sistema religioso retira de novo esse sentido, ao agir de forma estratégica, no sentido habermasiano. A lógica da divulgação é eminentemente publicitária; o discurso é ritualizado e manipulatório (SIGNATES, 1999). E, na lógica do jogo identitário, a expectativa dos públicos constituídos por fiéis é especular: as mídias são valorizadas somente se cumprem o papel de espelhos, os quais os fiéis observam a fim de enxergarem a si mesmos, numa perspectiva contrária à da alteridade.

Interessante demorar-nos um pouco mais nessa peculiaridade incomunicacional da divulgação, isto é, em sua natureza especular, a fim de compreender o modo específico como a tensão dogma/vínculo aí se estabelece. De um lado - o lado do dogma -, surpreendemos sempre a exigência identitária da fidelidade às interpretações hegemônicas e estabelecidas, contra as quais não é possível se posicionar, sem rupturas ou crises com a própria identidade religiosa. De outro lado, o do vínculo, se encontram as transformações tecnológicas e sociais dos processos comunicacionais que operam as redes de socialização e sociabilidade do presente, que terminam por estabelecer exigências superpostas às necessidades de vínculo que o campo religioso precisa atender, para garantir o compartilhamento de seus sentidos e a sobrevivência de suas tradições.

Tal tensionamento, usualmente, tem sido resolvido pela disjunção conteúdo/forma no interior dos processos de divulgação. Em outras palavras, as movimentações comunicacionais no sentido da divulgação ou do compartilhamento dos significados sagrados com os diferentes públicos leigos se dão pelo enrijecimento dos conteúdos (preservação da dogmática) e pela adequação dos formatos, assumindo tecnologias, técnicas e linguagens da comunicabilidade social e historicamente estabelecida, dentro de limites contextualmente estabelecidos. É possível perceber isso em praticamente todas as denominações religiosas, embora cada uma delas não raro demonstre limites nessa adequação, conforme a natureza mais ou menos conservadora de suas práticas rituais. Isso porque a adequação de práticas comunicacionais a modos de fazer típicos das formas midiáticas estabelecidas não raro determina alterações ritualísticas que podem implicar questionamentos de grupos internos, para os quais as tradições sejam caras. Neste estudo, várias pesquisas sobre as novas igrejas midiáticas, por exemplo, têm demonstrado como missas e cultos televisionados transformam (ou deformam, conforme o viés interpretativo) 
as liturgias tradicionais. As adequações de denominações tradicionais a ritos midiáticos, estilos musicais e até a uso de instrumentos musicais novos, nas ritualísticas religiosas contemporâneas, não se dão sem conflitos internos, críticos à submissão a lógicas de mercado e do entretenimento (GASPARETTO, 2009; PATRIOTA, 2009; FAUSTO NETO, 2004).

\section{c) Conversionismo}

A radicalidade do discurso estratégico e não comunicacional ancorado no dogma está, contudo, em outra modalidade: a da conversão religiosa. Como estudamos em outro trabalho (SIGNATES, 1999), o discurso conversionista é eminentemente estratégico, mais do que os anteriores, justamente porque busca o "outro" da religião (aquele que não compartilha a mesma ideologia) com o exclusivo e imediato propósito de "mesmificá-lo". A relação simbólica instaurada jamais se realiza como diálogo, no sentido ético do termo, isto é, os interlocutores não se enxergam como iguais. $\mathrm{O}$ sujeito religioso formula o discurso do convencimento e objetiva exclusivamente a aceitação de alter, fechando-se desde o início para toda e qualquer escuta ou aprendizado, exceto aquele que revele as fragilidades do pensamento ou do argumento do outro, com o explícito propósito de demoli-lo.

Entretanto, dessa constatação básica inicial não se deve inferir tratar-se de uma discursividade inteiramente fechada e autóctone. A tensão se mantém, embora o dogma continue funcionando como pressuposto, convertido em objetivo estratégico da interação instaurada. Como ocorre na forma divulgacionista, a conversionista precisa construir o vínculo, para que a atuação convincente seja praticada, e esse contato se opera por concessões específicas, empiricamente observáveis.

Podem ser apontadas duas modalidades que funcionem como padrões comunicacionais de atuação, na prática conversionista: o debate público e a relação face a face. O primeiro constitui uma espécie de modalidade intermediária entre o divulgacionismo e o conversionismo, embora prefiramos classificá-lo como modo do último, em razão da modalidade relativamente dialógica que o caracteriza, em face da disputa pública que eventualmente esteja instaurada. Já o segundo, o da relação face a face, é a modalidade tradicional do conversionismo.

O primeiro padrão, o do debate público, se define pela ida de agentes religiosos à esfera pública, a fim de disputar sentidos e regras sociais, cuja orientação se tornou, por alguma razão, dogmaticamente relevante. É o 
caso típico da busca por aprovação de leis e regulamentos que determinem ou protejam costumes, atitudes ou práticas sociais específicas, nas quais a dogmática religiosa tenha interesse ético, moral ou de outra natureza. No Brasil, e em outros países, as questões relacionadas ao aborto, à homossexualidade e à bioética têm sido caras às religiões, razão pela qual seus representantes invariavelmente se mobilizam em grupos de pressão junto aos parlamentos e tribunais constitucionais, a fim de fazer valer a permanência ou a modificação das regras sociais, na direção de posições dogmaticamente estabelecidas. Nesses casos, emerge quase sempre o debate político e sociológico sobre o Estado, especialmente no que respeita à reivindicação moderna da laicidade ou da secularização (GIUMBELLI, 2008)

Em interessante trabalho no qual avalia as relações entre os cidadãos seculares e os cidadãos religiosos, no embate da esfera pública, Habermas (2007) destaca as atitudes discursivas a que lançam mão os agentes religiosos, para fazerem valer seus argumentos na arena comum estabelecida pelo Estado democrático de direito numa sociedade relativamente secularizada. Segundo ele, os religiosos, para argumentarem com efetividade, se veem diante da necessidade de encontrar enfoques epistêmicos que sejam, ao mesmo tempo, abertos às mundividências, às outras religiões, aos saberes seculares, aos saberes especializados e, ainda, aos argumentos seculares que gozam de precedência na arena política. De acordo com o autor alemão, tais condições somente são alcançadas se conseguirem correlacionar as suas próprias ideias religiosas a outras concepções religiosas, aos progressos do conhecimento científico autônomo e ao "individualismo igualitário do direito da razão e da moral universalista no contexto de suas respectivas doutrinas abrangentes" (HABERMAS, 2007, p. 155). Em outras palavras, para Habermas, os representantes do dogma, perante a arena do debate público, precisam adequar seus discursos às condições plurais dessa arena, a fim de evitar a perda da força de seus argumentos pelo isolamento argumentativo de uma fala exclusiva para os convertidos. E, nesse caso, tais adequações não se dão apenas nos formatos, como na modalidade típica da divulgação, de que já tratamos, mas também nos conteúdos e nos modos como são tratados, restando o interesse dogmático posicionado quase exclusivamente nos objetivos estratégicos da empreitada. Um caso típico no Brasil dessa inflexão discursiva pode ser encontrado no modo como o pastor Silas Malafaia, uma das principais lideranças evangélicas do país, em 2015, se apresentou como psicólogo ao debate sobre a questão 
da homossexualidade, num conflito direto com o Conselho Federal de Psicologia (CAMPOS, GUSMÃO E MAURÍCIO JÚNIOR, 2015; DE FREITAS E PIASSON, 2017).

O conversionismo típico, contudo, encontra-se na relação face a face do ator religioso com o sujeito profano, com esse propósito específico. Tratase da forma mais usual e corrente do proselitismo religioso, momento que, em termos tipicamente evangélicos, o "pescador" sai em busca de efetuar a captura de novos fiéis. A metáfora da pescaria parece perfeita para descrever o tipo de relação que se instaura, revelando, novamente, a natureza estratégica da discursividade instaurada. Entretanto, não há que se fazer juízo moral dessa relação, uma vez que a conversão religiosa, tal como testemunham diversos estudos a respeito, trabalha diretamente com as identidades fragmentadas em jogo e contribui, especialmente junto às comunidades vulneráveis, como doentes e presos, com diferentes formas de reajustamento e ressocialização dos sujeitos convertidos. "Os detentos, agora "nascidos de novo" (...), procuram se distinguir da "massa carcerária" e tentam estabelecer uma "comunidade de irmãos" dentro da prisão. Nesse caso, a conversão representa uma ruptura com sua história pessoal” (LOBO, 2005, p. 76).

Importante, portanto, evitar enrijecer teoricamente os conceitos, ou mesmo os polos da tensão dogma/vínculo, ao se pensar as modalidades de conversão religiosa. Uma visão antropológica, mais generosa, do conversionismo, como a de Banaggia (2009), leva em consideração esse episódio como uma espécie de "encontro entre culturas" e identifica que não se trata, em momento algum, de uma transformação absoluta de uma coisa em outra coisa, na qual o polo dogmático e conversionista saia ileso e o outro, absolutamente reduzido ao primeiro. Com razão, pensa o autor que "os grupos humanos não podem ser considerados como uma tabula rasa, recebendo influências culturais externas de modo irrefletido" (BANAGGIA, 2009 , p. 202). Um modelo chamado de "substituição", no qual se presume uma transformação radical e total de uma cultura à outra, não se sustenta diante dos resultados das pesquisas etnográficas, restando como fundamentos pressupostos das transformações observadas, segundo o autor:

“...de um lado, culturas que só aceitam conjugar-se com outras em seus próprios termos; do outro, culturas que desejam adotar uma alteridade conservando-a da melhor forma possível, em alguma medida apagando-se a si mesmas; entre os extremos, as concessões mútuas em processos aparentemente 
mais tolerantes. (...) A questão passa a ser o grau de interpenetração entre elas, assim como o tipo de convivência que se mostra possível, com conflitos ou não” (BANAGGIA, 2009, p. 208).

De todo modo, de um ponto de vista comunicacional, não parece possível inferir, por razões etnográficas ou antropológicas, que o conversionismo seja dialógico. O episódio de conversão pressupõe uma assimetria que de alguma forma beneficia o conversor, em face do convertido. O que não significa, contudo, que o processo comunicacional deixe, por isso, de ser "tentativo" (BRAGA, 2010), isto é, de ser um processo sempre dependente das produções mútuas de sentido dos interlocutores em interação e não transmissionista, no sentido cibernético do termo. Tal peculiaridade torna toda e qualquer conversão religiosa uma ação de tipo estratégico e, nesse sentido, autoritário, porém definida como "uma espécie de transformação ou translação, uma relação entre versões, elas mesmas em efervescência contínua” (BANAGGIA, 2009, p. 218).

\section{d) Dialogismo}

Diante de tantas modalidades discursivas que operam em configurações que dificultam o processo comunicacional, em que termos se pode esperar o diálogo intra e inter-religioso? Essa é a questão empírica de pesquisa sobre a qual nos debruçamos, hoje. E ela se desdobra em uma série de indagações de elevada importância para este estudo. Até que ponto o que se denomina "diálogo" nas religiões não se revela apenas uma área de interface de interesses determinados, isto é, a configuração de possíveis alianças de caráter político (como por exemplo, na luta das diferentes denominações cristãs contra as legislações de aborto), sem que a dialogicidade, como alteridade e aprendizado mútuo efetivamente se estabeleça? Em outro aspecto, até que ponto a relação com o "outro" do religioso instaurada como diálogo não esconde propósitos efetivamente estratégicos e não comunicacionais, resultando em apenas uma mimetização da dialogicidade? O que é, enfim, a comunicação, para a experiência religiosa, em suas diversas facetas?

Compreendemos que tais questões não podem ser respondidas senão empiricamente, e considerando as lógicas específicas das situações sociais de alteridade em que o religioso efetivamente se encontre. Embora se possa deduzir, como se fez neste trabalho, que as lógicas da catequese, da divulgação e da conversão caminham no sentido de fechamento comunicacional, em 
direção a processos dogmatizantes, não há que se generalizar nem totalizar tais configurações, pois, como se buscou deixar claro neste trabalho, é grave o risco de conclusões ex ante, que deixem de considerar outras variáveis intervenientes e se revelem depois contrafáticas, ou, até mesmo, que neguem a condição indeclinável de que as relações de linguagem não constituem "transmissões" de conteúdo e sim negociações de sentido, mesmo que em ambientes de radicalização comunicacional, autoritariamente demarcados ou em condições de ameaça ou violência.

O debate da dialogicidade constitui, por isso, muito menos uma questão técnica e muito mais uma visada ética, lançada sobre a análise das interações comunicacionais. Trata-se de um problema que visita diferentes áreas das ciências, podendo ser encontrado em disciplinas as mais díspares, como a engenharia da produção e a administração (JUSTEN e MORETTO NETO, 2012) até a psicologia, numa perspectiva fenomenológica (DE SOUZA et al., 2013). No campo dos estudos de religião, trata-se de um tema de elevada contemporaneidade, especialmente por conta das condições históricas da globalização da informação, que interconecta culturas e religiosidades em perspectivas conflitivas nem sempre abertas à compreensão mútua. Os debates sobre o dialogismo religioso e, nesse âmbito, acerca das hipóteses ecumênicas, constituem amplas possibilidades de pesquisa, no contexto das sociedades democráticas capitalistas, onde a pluralidade religiosa multiplica os desafios conflitivos (NAVARRO, 1995; HORTAL, 1996; BRAKEMEIER, 2001; WOLFF, 2005).

A perspectiva dialógica recebe diversas contribuições teóricas, entre as quais, para os estudos de comunicação e religiosidade, se pode destacar a rica abordagem advinda da filosofia da alteridade, que soergue o questionamento ético da relação ao outro, a partir de Buber (1982) e Lévinas (1997), e que têm se desdobrado em interessantes aportes nas ciências sociais e humanas. A psicologia social de Moscovici, por exemplo, especifica dois tipos de alteridade: a "alteridade de dentro" e a "alteridade de fora" (JODELET, 1998), para distinguir diferentes possibilidades de diálogo com os incluídos no grupo social e com os externos ao grupo social, o que, em termos religiosos, implica nos estudos das dialogicidades intra-religiosa e interreligiosa. Da filosofia social, é relevante destacar a contribuição de Jürgen Habermas, já citada aqui, cuja abordagem normativa especifica "pretensões de validade", isto é, pressuposições a que os sujeitos em interação têm que considerar atendidas para que invistam numa relação de tipo comunicativo 
(são elas: inteligibilidade, verdade, veracidade e retidão normativa). Antes mesmo dos estudos habermasianos, com grande proveito para os estudos de educação e linguagem, podem ser citados Baktin (1988) e Freire (2013), como precursores dos estudos da dialogicidade, na perspectiva de uma postura pragmática dos sujeitos em interação. Dessas abordagens, emergem relevantes possibilidades de estudo da religiosidade, como um dos mais importantes modos de compreensão do mundo e de estabelecimento de vínculos, nos quais, sem deixar de existir, a tensão entre dogma e vínculo adquirem aspectos comunicacionais éticos singulares, dentro dos quais os sujeitos religiosos conseguem operar a compreensão mútua dentro de um quadro ético de respeito à religiosidade de alter, propiciando uma situação social em que a religiosidade se converte numa ética de espiritualidade que passa a contar com o múltiplo e com uma simbólica de paz, na qual a conflitualidade dogmática ou ritual evita o quanto pode se transformar em violência, ainda que simbólica.

\section{O proveito do especificamente comunicacional}

Mais importante, neste momento, do que, neste breve ensaio, oferecer respostas às indagações empíricas feitas, é a percepção de que o contexto religioso é um interessante espaço simbólico de observação do comunicacional.

Por um lado, a religião mantém uma extrema dependência de sentidos comunicacionais (definidos como o simbólico em movimento e conexão contínua e contraditória), especialmente depois que o Iluminismo e a Modernidade fundaram a laicidade dos sentidos públicos e arrancaram das instituições religiosas a quase totalidade de seus instrumentos de exercício de poder (armas e dinheiro, viabilizados por um vínculo orgânico com as instituições estatais). Todas as religiões devem operar na competição pela legitimidade junto à sociedade, por meio dos dispositivos retromencionados e, por essa razão, se tornaram instituições de poder simbólico por excelência.

A religião, contudo, não perdeu - ao menos não completamente seu viés totalizante. A fé e a vida religiosa alcançam a existência como um todo, estabelecendo regras e parâmetros ao fiel, que vão desde a produção da mundividência até as práticas da vida cotidiana. Mas, isso o fazem sem poder material, pois, na modernidade, as instituições detentoras desse tipo de poder, especialmente o Estado, destituíram as organizações religiosas de seu exercício, momento em que tais organizações passaram a se tornar 
reféns da capacidade de controlar a circulação simbólica dos sentidos do sagrado e de suas repercussões - totalizantes - sobre o mundo profano. Eis por que, dependente completa dos sentidos comunicacionais, as instituições religiosas devem controlá-los, vetá-los, conduzi-los, para que sobrevivam, como sustentadores de identidades culturais próprias.

Essa dupla característica, de natureza contraditória, é fundadora de uma tensão permanente e aparentemente insolúvel na ordem do religioso, e que opera com extremos, em razão das próprias peculiaridades de engajamento, pois constituem formações identitárias, ainda que reativamente fragilizadas pela modernidade, e não apenas escolhas fortuitas ou com pouca relevância ética, como no mundo do consumo. Estar religioso não é em nada parecido com o consumir um produto, ainda que pareça, falsamente, que as escolhas de conversão sejam tão disponíveis quanto chocolates em gôndolas de supermercados. Tornar-se religioso ou se converter ainda é, em grande sentido, transformar-se identitariamente.

Uma tensão, de tipo especificamente simbólico, e que é levada ao limite, na conflitualidade entre o sistema religioso e a vivência religiosa, opera no sentido de conferir uma visibilidade significativa aos elementos especificamente comunicacionais, seja na perspectiva do estudo de sua existência e presença nos relacionamentos empiricamente observados, seja na da constatação de sua inexistência, lá onde os discursos autorizados afirmam sua presença. E, nessa busca pela revelação de suas possibilidades e de seus limites, as categorias do especificamente comunicacional emergem, tornandose melhor disponíveis à análise e elevando a expectativa pela construção de uma teorização consistente, na qual desponte o objeto específico da ciência da comunicação.

\section{Referências}

AZEVEDO, Cristiane A. A procura do conceito de religio: entre o relegere e o religare. Religare, João Pessoa, v. 7, n. 1, p. 90-96, mar. 2010.

BAKTIN, Mikhail. Marxismo e filosofia da linguagem. São Paulo: Hucitec, 1988.

BANAGGIA, Gabriel. Conversão, com versões: a respeito de modelos de conversão religiosa. Religião e Sociedade, Rio de Janeiro, v. 29, n. 1, p. 200-222, 2009.

BOURDIEU, Pierre. O poder simbólico. São Paulo: Bertrand Brasil/Difel, 1989.

BRAGA, José L. Nem rara, nem ausente: tentativa. Matrizes, São Paulo, v. 4, n. 1, p. 65-81, jul./dez. 2010. 
BRAKEMEIER, Gottfried. Ecumenismo: repensando o significado e a abrangência de um termo. Perspectiva Teológica, Belo Horizonte, v. 33, n. 90, p. 195-216, 2001.

BUBER, Martin. Do diálogo e do dialógico. São Paulo: Perspectiva, 1982.

CAMPOS, Roberta B. C.; GUSMÃO, Eduardo H. A.; MAURÍCIO JÚNIOR, Cleonaldo G. de B. A disputa pela laicidade: Uma análise das interações discursivas entre Jean Wyllys e Silas Malafaia. Religião e Sociedade, Rio de Janeiro, v. 35, n. 2, p. 165-188, 2015.

DE FREITAS, Marta H.; PIASSON, Douglas L. Religião, religiosidade e espiritualidade: repercussão na mídia e formação profissional em psicologia. Esferas, Ano 5, n. 8, p. 103112, jan./jun. 2016.

DE SOUZA, Mariane L.; OLIVEIRA, Manoela Z.; DA SILVEIRA, Amanda; GOMES, William B. A lógica da dialogicidade narrativa no repertório de posições pessoais. Psicologia: Teoria e Pesquisa. Brasília, v. 29, n. 3, p. 321-329, jul./set. 2013.

FAUSTO NETO, Antonio. A religião teleterapeutizante: discursividades dos templos midiáticos. Revista Fronteiras: Estudos Midiáticos, v. 6, n. 2, p. 25-46, jul./dez. 2004.

FOUCAULT, Michel. Microfísica do poder. Rio de Janeiro: Graal, 1997.

FREIRE, Paulo. Extensão ou comunicação? Rio de Janeiro: Paz e Terra, 2013.

GASPARETTO, Paulo R. Midiatização da religião: processos midiáticos e a construção de novas comunidades de pertencimento: estudo sobre a recepção da TV Canção Nova. São Leopoldo: Unisinos, 2009 (Tese de doutoramento).

GIUMBELLI, Emerson. A presença do religioso no espaço público: modalidades no Brasil. Religião e Sociedade, Rio de Janeiro, v. 28, n. 2, p. 80-101, 2008.

GOMES, Wilson. Transformações da política na era da comunicação de massa. São Paulo: Paulus, 2004.

HABERMAS, Jürgen. Entre o naturalismo e a religião: estudos filosóficos. Rio de Janeiro: Tempo Brasileiro, 2007.

HABERMAS, Jürgen. Teoria do agir comunicativo. São Paulo: Martins Fontes, 2012.

HORTAL, Jesús. E haverá um só rebanho: história, doutrina e prática católica do ecumenismo. São Paulo: Loyola, 1996.

JODELET, Denise. A alteridade como produto e processo psicossocial. In: Representando a alteridade. Petrópolis: Vozes, 1998 (p. 47-67).

JUSTEN, Carlos E.; MORETTO NETO, Luís. Do economicismo à dialogicidade: as contribuições do paradigma da ecologia profunda e da noção de gestão social para a temática da sustentabilidade empresarial. Cadernos Ebape.br, Rio de Janeiro, v. 10, n. 3, p. 736-750, set. 2012.

LAUAND, L. J. A filosofia da educação no novo catecismo católico. I Congresso Latino de Filosofia da Educação, Rio de Janeiro, 2000. Link: http://www.hottopos.com/convenit3/ jeanlaua.htm Acesso em 10/11/2018. 
LÉVINAS, Emmanuel; PIVATTO, Pergentino S. Entre nós: ensaios sobre a alteridade. Petrópolis: Vozes, 1997.

LOBO, Edileuza S. Ovelhas aprisionadas: a conversão religiosa e o "rebanho do senhor" nas prisões. Debates do NER, Porto Alegre, ano 6, n. 8, p. 73-85, jul./dez. 2005.

NAVARRO, Juan B. Para compreender o ecumenismo. São Paulo: Loyola, 1995.

PATRIOTA, Karla R. M. P. Um show destinado às massas: uma reflexão sobre o entretenimento religioso na esfera midiática. Revista Tomo, n. 14, p. 181-202, 2009.

RODRIGUES, Adriano D. Estratégias da Comunicação: questão comunicacional e formas de sociabilidade. Lisboa: Presença, 2001.

SANTOS, Boaventura. Pela mão de Alice: o social e o político na pós-modernidade. São Paulo: Cortez, 1997.

SIGNATES, Luiz. A ética do discurso religioso, entre o estratégico e o comunicativo. Intercom, v. 99, 1999. Link: http://www.portcom.intercom.org.br/pdfs/33fa11933d9717e6 bec9e9c869beba05.PDF Acesso em: 11/11/2018.

SIGNATES, Luiz. A sombra e o avesso da luz: Habermas e a comunicação social. Goiânia: Kelps, 2009.

THOMPSON, John B. A mídia e a modernidade: Por uma teoria social da mídia. Petrópolis: Vozes, 2009.

VAZ, Francisco A. L. O catecismo no discurso da ilustração portuguesa do século XVIII. Cultura. Revista de História e Teoria das Ideias, v. X, Lisboa, p. 217-240, 1998.

WOLFF, Elias. Igrejas e ecumenismo: uma relação identitária. Estudos Teológicos, São Leopoldo, v. 45, n. 2, p. 18-30, 2005.

Submetido em: 17-6-2017

Aceito em: 25-11-2018 